\title{
O controle da transmissão transfusional
}

\author{
Control of transfusional transmission
}

\author{
Helio Moraes-Souza**** Márcia Maria Ferreira-Silva***
}

\begin{abstract}
RESUMO
A alta prevalência de doadores chagásicos nos bancos de sangue do Brasil (6,9\%) e da América Latina (6,5\%), nas décadas de 60 e 70 , aliada ao combate ao vetor a partir dos anos setenta, fez com que a doença de Chagas transfusional, a partir da década de oitenta, se tornasse o principal mecanismo de transmissão da doença na maioria dos países endêmicos. Contudo, os resultados altamente favoráveis do combate ao vetor e da cobertura sorológica dos doadores, reduziu a prevalência de soropositividade para 0,2\% e 1,3\%, respectivamente, no Brasil e América Latina e o índice de transmissão anual, via transfusão de sangue no Brasil, de 20.000 para 13 em quatro décadas. Entretanto, paralelamente aos grandes avanços obtidos pelos países endêmicos, a doença de Chagas alcançou, via processo migratório, os países não endêmicos da América do Norte e da Europa, além do Japão e Austrália, colocando em risco os receptores de sangue destes países e transformando a doença de Chagas num problema de saúde global. A segurança transfusional, propiciada pela triagem sorológica, trouxe, porém outro importante problema, qual seja, a alta proporção de reações inconclusivas e dois grandes desafios: o significado de tais exames e que orientação proporcionar ao doador. Contudo, as estratégias adotadas pelos países não endêmicos e os avanços alcançados pelos endêmicos, prenunciam o breve, auspicioso e intensamente sonhado controle vetorial e transfusional da doença de Chagas.
\end{abstract}

Palavras-chaves: Transfusão de sangue. Doença de Chagas. Transmissão transfusional. Medidas de controle.

\begin{abstract}
The high prevalence of chagasic blood donors in blood centers in Brazil (6.9\%) and in Latin America (6.5\%) in the 60's and 70's, together with the combat to the vector since the 70's have made transfusion Chagas disease the main mechanism of the disease transmission in the 80's. However, the highly favorable results achieved to eliminate the vector and the serologic screening of blood donors, reduced the prevalence of serum positivity to $0.2 \%$ and $1.3 \%$, respectively and the rate of annual transmission through blood transfusion from 20.000 to 13 in four decades in Brazil. Nevertheless, despite outstanding advancements in endemic countries, Chagas disease reached, via migration, non-endemic countries in North America and Europe besides Japan and Australia, placing their blood recipients at risk and turning Chagas disease into a worldwide health problem. Transfusion safety through serologic selection raised another big issue i.e. high proportion of inconclusive reactions as well as two great challenges: the meaning of such exams and what guidelines to provide the donor. However, the strategies adopted by non-endemic countries and the advancements achieved by endemics so far forecast the highly wished vector and transfusion control of Chagas disease.
\end{abstract}

Key-words: Blood transfusion. Chagas' disease. Transfusional transmission. Measurement control.

A possibilidade de transmissão da doença de Chagas através da transfusão de sangue foi aventada em $1936^{1}$ na Argentina e confirmada em 1952 no Brasil ${ }^{2}$.

O processo migratório no sentido campo-cidade, com o início da industrialização do Brasil, a partir da década de cinquenta, promoveu a urbanização da doença e foi responsável pela alta prevalência de doadores chagásicos nos bancos de sangue do país, atingindo índices de aproximadamente $10 \%{ }^{3}$. Quadro semelhante foi observado gradativamente em todos os países endêmicos ${ }^{4}$.

A alta prevalência de indivíduos chagásicos nos centros urbanos e a inexistência de programas de controle, fez com que a transmissão transfusional da tripanossomíase cruzi fosse responsável, na década de setenta, por aproximadamente 20 mil novos casos anuais da doença apenas no Brasil ${ }^{5}$.

Com o gradativo controle da transmissão natural, especialmente pela interrupção da transmissão vetorial,completa

*Professor Titular de Hematologia e Hemoterapia, Universidade Federal do Triângulo Mineiro. Uberaba, MG. **Pesquisador da Fundação Hemominas, Belo Horizonte, MG. ***Mestre e doutoranda em Patologia Clínica pela Universidade Federal do Triângulo Mineiro, Uberaba, MG.

Endereço para correspondência: Prof. Helio Moraes-Souza. Hemocentro Regional de Uberaba/HRU. Av. Getulio Guarita 250, Abadia, 38025-440 Uberaba, MG.

Tel: 5534 3312- 5077.

e-mail: helio.moraes@dcm.uftm.edu.br ou parcialmente, em alguns dos países endêmicos, a transfusão de sangue passou a ser o principal mecanismo de disseminação da doença nestas áreas ao longo das décadas de 80 e 90.

Levantamento realizado em vários países da América Latina demonstrou que no caso do Brasil a prevalência da infecção chagásica entre crianças e jovens de 7 a 14 anos, experimentou uma redução de $18,5 \%$ na década de 80 para $0,2 \%$ na década de $90^{6}$. Um estudo mais recente, realizado no ano de 2007 , em população de crianças entre 0 a 5 anos, que totalizou 94 mil amostras de sangue coletadas, demonstrou uma soroprevalência da doença de Chagas neste grupo de $0 \%$, o que pode ser interpretado como a confirmação da interrupção da transmissão da doença de Chagas no Brasil ${ }^{7}$.

Como a maioria dos doadores de sangue está geralmente concentrada na faixa etária dos 18 aos $35 \operatorname{anos}^{8}$, o menor número de candidatos chagásicos nos bancos de sangue, somado à obrigatoriedade da triagem sorológica, imposta na quase totalidade dos países endêmicos nos últimos anos, vem reduzindo a prevalência entre os doadores e, consequentemente, uma importante redução do risco da transmissão transfusional da doença de Chagas em toda a América Latina ${ }^{3}$ (Tabela 1). Especificamente no Brasil, enquanto nos anos cinquenta a prevalência média de sorologia positiva para Trypanosoma cruzi era de 8,3\%, nos anos sessenta e setenta caiu para $6,9 \%$ e, no final dos anos oitenta e início de noventa, para $3,2 \%{ }^{9}$. Levantamentos mais recentes apontam queda da 
TABELA 1 - Prevalência de sorologia positiva para doença de Chagas em doadores de sangue dos países endêmicos da América Latina, no ano de 1950, décadas de 60-70, 80-90, e ano de 2005.

\begin{tabular}{|c|c|c|c|c|}
\hline \multirow[b]{2}{*}{ Países } & \multicolumn{4}{|c|}{ revalência sorológica para Trypanosoma cruzi (por década/ano) } \\
\hline & $50^{*}$ & $60-70^{* *}$ & $80-90^{* *}$ & $2005^{* * *}$ \\
\hline Argentina & - & 5,56 & 8,62 & 2,47 \\
\hline Belize & - & - & - & 0,40 \\
\hline Bolívia & - & - & 22,47 & 8,00 \\
\hline Brasil & 8,29 & 6,96 & 3,17 & 0,21 \\
\hline Chile & - & 5,09 & 7,47 & 0,60 \\
\hline Colômbia & - & 6,50 & 7,50 & 0,80 \\
\hline Costa Rica & - & 7,69 & 10,10 & 0,14 \\
\hline El Salvador & - & - & 1,00 & 2,42 \\
\hline Equador & - & 3,21 & 0,28 & 0,36 \\
\hline Guatemala & 8,56 & - & 5,00 & 0,01 \\
\hline Guianas & - & - & - & 2,31 \\
\hline Honduras & - & 28,00 & 11,60 & 1,40 \\
\hline México & - & 4,40 & 17,50 & 0,60 \\
\hline Nicarágua & - & - & - & 0,90 \\
\hline Panamá & - & - & - & 0,90 \\
\hline Paraguai & - & - & - & 3,20 \\
\hline Peru & - & 5,82 & - & 0,57 \\
\hline Uruguai & - & 5,50 & 1,77 & 0,47 \\
\hline Venezuela & 10,9 & - & 1,70 & 0,78 \\
\hline América Latina & 8,41 & 6,49 & 2,63 & 1,28 \\
\hline
\end{tabular}

prevalência ainda mais consistente. Documento da Organização Mundial da Saúde de 2006 revela índice de prevalência de doadores chagásicos para toda a América Latina de apenas 1,3\% (queda de 78,7\% em relação àquela observada há 30 anos) e para o Brasil de 0,2\% (queda de $97 \%$ no mesmo período) ${ }^{10}$.

Corroboram estes dados, estudos de prevalência da infecção chagásica em bancos de sangue realizados em vários estados do Brasil. Em Pernambuco, um levantamento da década de 70 evidenciou prevalência de 4,4\% entre doadores de um hospital de Recife. Após três décadas, um recente estudo realizado na Fundação HEMOPE (Hemocentro de Pernambuco) encontrou um valor de $0,2 \%$ de prevalência, indicando que houve um decréscimo médio de 55 doadores soropositivos por ano ${ }^{11}$. No Rio Grande do Sul, estado altamente endêmico até duas décadas atrás, registrou-se, em um estudo de 1979, uma prevalência de 3,3\% entre doadores da Santa Casa de Pelotas ${ }^{12}$, índice que atualmente caiu para $0,5 \%{ }^{13}$. Em São Paulo, no início da década de 80 , esta prevalência era de $2,9 \%^{3}$, já em 2003 , o índice de descarte por T. cruzi na Fundação Pró Sangue foi de $0,2 \%{ }^{14}$. No Hemocentro Regional de Uberaba, MG, enquanto na década de sessenta 16,6\% dos doadores eram chagásicos ${ }^{15}$, em 2005 apenas $0,3 \%$ dos doadores foram inaptos sorológicos para esta endemia ${ }^{8}$.

Resultados tão auspiciosos são consequência, sobretudo, de políticas de saúde estaduais, nacionais e macrorregionais. Como exemplo de políticas estaduais, merece destaque o programa de combate sistemático ao triatomíneo implementado pelo estado de São Paulo na década de sessenta - primeiro estado brasileiro a se tornar livre da endemia.
Importantes políticas nacionais de controle da doença de Chagas podem ser identificadas especialmente no Brasil, Chile e Uruguai, este último certificado pela Organização Panamericana de Saúde como livre da transmissão vetorial e transfusional em 1997, o Chile livre da transmissão vetorial em 1999 e o Brasil em $2006^{10}$. Também atesta os exitosos resultados obtidos, a queda da prevalência da infecção chagásica em jovens, entre as décadas de 80 e 90, nos seis países do Cone sul, com quedas que oscilaram de $68,1 \%$ no Paraguai a $99,8 \%$ no Brasil ${ }^{7}$.

Especificamente, em relação ao Brasil, a criação pelo Ministério da Saúde do Programa Nacional de Sangue e Hemoderivados em 1980, resultou na implantação gradativa de uma rede pública estadual hierarquizada de serviços de hemoterapia-HEMORREDE. Os investimentos financeiros feitos nesta hemorrede atraíram recursos humanos qualificados, com grande reflexo na qualidade da triagem clinica e sorológica dos doadores de sangue. A melhora técnico-científica e as ações de vigilância sanitária junto a estes serviços de hemoterapia públicos e privados e ainda, o controle da transmissão natural, reduziu a prevalência de sorologia não negativa (positiva ou indeterminada) para T. cruzi entre os doadores de sangue do país de $6,9 \%$ para $0,2 \%$ em aproximadamente 30 anos $^{10}$.

Destaque especial deve ser dado às iniciativas macroregionais implementadas pelos governos dos diversos países endêmicos, em parceria com a comunidade científica nacional, contando com o estímulo e o apoio estratégico e político da Organização Panamericana da Saúde (OPS).

Delineadas pela comunidade cientifica, as estratégias de controle foram centradas no combate sistemático ao vetor, melhoramento das moradias, educação sanitária das comunidades e cobertura sorológica dos doadores de sangue. Sob a coordenação da OPS, formalizou-se então, em Brasília, em 1991, a Iniciativa do Cone Sul para eliminação do Triatoma infestans e controle da transmissão transfusional da doença de Chagas, envolvendo Argentina, Bolívia, Brasil, Chile, Paraguai e Uruguai ${ }^{4}$. As intenções da comunidade científica, prontamente assimiladas e incorporadas pela OPS, eram garantir a continuidade/sustentabilidade dos programas já iniciados na Argentina, Brasil, Chile e Uruguai (ameaçados por problemas de descentralização e falta de recursos e de prioridade, especialmente frente à dengue e outros problemas endêmicos emergentes) e alavancar definitivamente as ações de controle na Bolívia e Paraguai ${ }^{16}$. Seguindo-se à Iniciativa do Cone Sul, foram implementadas as Iniciativas dos Países do Pacto Andino e da América Central e Belize em 1999, a Iniciativa do México em 2003 e a Iniciativa Amazônica em 2004 ${ }^{16}$.

Em países em que a cobertura sorológica é universal, como o Brasil, o risco da transmissão transfusional se restringe àqueles raros casos de falha de sensibilidade dos testes sorológicos (sensibilidade hoje superior a 99,5\%) e a eventuais erros clericais. Resultados de um amplo programa de controle externo de qualidade da sorologia para doença de Chagas realizado no Brasil, no final dos anos 90, em 116 serviços hemoterápicos públicos (hemocentros) e privados (bancos de sangue), demonstrou falha na identificação da infecção chagásica de $1,6 \%{ }^{17}$. Extrapolando tal performance para o ano de 2005 - quando a cobertura sorológica no país já era de $100 \%$, a prevalência de sorologia positiva de 
$0,2 \%$ e foram realizadas aproximadamente 3.2 milhões de doações - 107 bolsas de sangue chagásico teriam sido liberados para transfusão e, aproximadamente, 13 receptores teriam se infectado. Estudos semelhantes desenvolvidos em vários países da América Latina, entre 1997 e 2000, encontraram 3,2\% de resultado falso-negativos ${ }^{18,19}$. Igualmente, extrapolando este índice de falha sorológica para aproximadamente 5,7 milhões de doadores submetidos à triagem sorológica (86,8\% das 6,6 milhões de doações anuais), frente a um índice de soropositividade de $1,3 \%$, teríamos 2.362 bolsas de sangue falso-negativas liberadas para transfusão e, aproximadamente, 330 infecções por falha de sensibilidade sorológica e/ou erro clerical. Se considerarmos as $900 \mathrm{mil}$ bolsas de sangue liberadas sem sorologia (13,2\% das bolsas coletadas em 2005) e a mesma prevalência de soropositividade (1,3\%), teríamos mais 11.520 bolsas de sangue contaminado liberado para transfusão e, estimativamente, mais 1.728 infecções que, somadas às 330 por falha sorológica, somariam 2.058 infecções chagásicas via transfusão de sangue anualmente. Estes resultados são, portanto semelhantes aos 2.247 casos apresentados no estudo realizado pelos técnicos da $\mathrm{OMS}^{10}$.

Paralelamente à melhora do panorama nos países endêmicos, vem sendo constatada a internacionalização da doença de Chagas, com sua difusão a países não-endêmicos pela transmissão por transfusão sanguínea. Estes fatos começaram a ser observados juntamente com os grandes fluxos migratórios da América Latina para a América do Norte, Europa, Japão e Austrália, especialmente a partir da década de oitenta ${ }^{4}$ e que se intensificaram muito nos últimos anos ${ }^{20}$.

0 risco de um paciente se infectar ao receber uma unidade de sangue de doador chagásico é variável. Nas regiões com altos índices de transmissão vetorial, com grande número de indivíduos infectados mais recentemente e com altas cargas parasitárias, como Santa Cruz, na Bolívia, chega a 49\%. Nos países com baixos índices de transmissão natural, como Argentina, Brasil, Chile e Uruguai oscilam entre 12\% e $18 \%$. Em países não endêmicos, o risco é ainda menor, como demonstram vários estudos retrospectivos desenvolvidos pela American Red Cross e o Food and Drug Administration (FDA), dos Estados Unidos da América do Norte ${ }^{21,22}$.

O risco de transmissão da doença de Chagas via transfusão de sangue, está na dependência dos seguintes fatores: a) presença do parasita no sangue ou componente transfundido; b) tipo e número de produto sanguíneo infectado transfundido; c) estado imunológico do receptor; d) nível de cobertura sorológica dos doadores e e) sensibilidade dos testes sorológicos empregados na seleção dos doadores ${ }^{16}$.

Ocorrida a transmissão, a infecção chagásica no receptor é geralmente assintomática e as raras formas agudas manifestam-se, quase que exclusivamente, nos pacientes imunossuprimidos. Nestes, como transplantados, aidéticos e pacientes em quimioterapia, além do maior risco de transmissão, a doença se manifesta na maioria dos casos de forma aguda e grave. Já nos indivíduos imunocompetentes, a infecção chagásica raramente se manifesta como fase aguda quando da transmissão transfusional, similarmente ao observado na transmissão natural. Quando ocorre, caracterizase por febre prolongada (não responsiva aos antibióticos), linfoadenopatia e hepatoesplenomegalia ${ }^{16}$.
Os pacientes infectados, quando não tratados, especialmente os imunocompetentes, podem recuperar-se espontaneamente em seis a oito semanas e evoluir para a fase crônica da doença. Todavia, manifestações neurológicas, como meningite e encefalite, insuficiência cardíaca e morte, podem advir na fase aguda da doença, sobretudo nos imunodeprimidos ${ }^{23}$. A predominância absoluta de infecção assintomática, explica o pequeno número de casos de transmissão transfusional bem documentados, (aproximadamente 300), frente a uma estimativa de ocorrência anual de 20.000 casos no Brasil e mais de 4.000 na Argentina na década de 70, várias centenas na Bolívia no final dos anos 90 e mais de 1.000 casos no México no ano $2000^{10,16}$.

Os dados disponíveis permitem concluir que o panorama da doença de Chagas na América Latina mudou sensivelmente, para melhor, desde a constatação de sua transmissão transfusional em $1952^{2}$. Assim é que, o número de infectados caiu de 16 milhões para 7,6 milhões; a soroprevalência de doadores de $8,4 \%$ para $1,3 \%$; a cobertura sorológica, praticamente inexistente há 40 chegou a $86,8 \%$ em toda a América Latina e de $100 \%$ em 13 dos 18 países endêmicos e o índice estimado de transmissão anual, via transfusão sanguínea, de aproximadamente 24 mil, apenas no Brasil e Argentina, para 2.247 em toda a América Latina em 2005 3,9,24.

Apesar da drástica melhora do panorama da doença de Chagas transfusional na América Latina e, sobretudo no Brasil, medidas de vigilância e controle são imprescindíveis para evitar o seu ressurgimento nos 13 países onde a cobertura sorológica é universal e deve ser ampliada nos seis outros países endêmicos. Nos não-endêmicos, parece ser necessário e suficiente, a triagem sorológica dos doadores de risco ${ }^{25}$, quais sejam, aqueles nascidos ou procedentes de zonas endêmicas e/ou filhos de mães chagásicas. Portanto, diante da atual baixa ocorrência de doadores chagásicos nos bancos de sangue, uma triagem sorológica, sistemática e universal, nos países endêmicos e, seletiva nos não endêmicos, empregando reagentes de alta sensibilidade, fará com que a doença de Chagas transfusional se torne, brevemente, uma rara iatrogenia hemoterápica ${ }^{26}$.

Contudo, paralelamente à baixa prevalência de doadores chagásicos, vem chamando a atenção a significativa proporção de doadores inaptos sorológicos em decorrência de reações inconclusivas, indeterminadas ou discrepantes. Três diferentes estudos desenvolvidos no Brasil evidenciaram índices de reações inconclusivas e/ou discrepantes que variaram de $53 \%$ a $69,6 \%$ dos inaptos sorológicos ${ }^{8,11,27}$. Nos Estados Unidos, diante de um índice de inaptidão sorológica de 0,012\%, em 3,5 milhões de doadores, no primeiro semestre de 2007, a confirmação da presença de infecção chagásica, pela técnica da radioimunoprecipitação (RIPA), foi feita em apenas 111 (0,004\%), apresentando portanto um índice de indeterminação de $74 \%{ }^{28}$.

Em estudo desenvolvido no Hemocentro Regional de Uberaba, com 60 doadores inaptos sorológicos (30 repetidamente positivos e 30 com resultados inconclusivos), enquanto $40 \%$ dos primeiros apresentaram hemocultura positiva, este método parasitológico de confirmação de infecção chagásica foi $100 \%$ negativo nos inconclusivos, evidenciando a baixa ou mesmo ausência de correlação entre reação inconclusiva e doença de Chagas $^{29}$. 
Portanto, as dificuldades na abordagem e condução de doadores com reações indeterminadas, muitas das quais, senão a quase totalidade, de não-chagásicos, e o significativo descarte de bolsas, possivelmente desnecessário, tornam evidente a necessidade da implementação de estratégias que permitam identificar, com segurança, o doador chagásico e minimizar ou mesmo eliminar resultados sorológicos duvidosos ou indeterminados. Tais estratégias devem consistir no desenvolvimento de testes sorológicos $100 \%$ específicos e/ou de exames confirmatórios práticos, rápidos e automatizáveis, passíveis de serem introduzidos nas rotinas dos bancos de sangue ou em serviços de referência de fácil acesso.

Entendemos que, apesar do desafio que os países não endêmicos vêm enfrentando, as estratégias por eles adotadas e os avanços alcançados pelos países endêmicos, entre eles o Brasil, prenunciam o breve, auspicioso e intensamente sonhado controle vetorial e transfusional da doença de Chagas.

\section{REFERÊNCIAS}

1. Mazza S, Montana A, Benetez C, Janzi EZ. Transmisión del Schizothypanum cruzi al niño por leche de la madre con enfermedad de Chagas. Mepra 1936; 28:41-46.

2. Freitas JLP, Amato Neto V, Sonntag R, Biancalama A, Nussenzweig V, Barreto JG. Primeiras ratificações de transmissão acidental da moléstia de Chagas ao homem por transfusão de sangue. Rev Paul Med 1952; 40:36-40.

3. Schmunis GA. Trypanosoma cruzi. The etiologic agent of Chagas' disease: status in the blood supply in the endemic and non endemic countries. Transfusion 1991; 31:547-557.

4. Schmunis GA. Tripanosomíase Americana: seu impacto nas Américas e perspectivas de eliminação. In: Dias JCP, Coura JR, editores. Clínica e terapêutica da doença de Chagas. Rio de Janeiro: Fiocruz Editora; 1997. p.11-23.

5. Dias JCP. Control of Chagas disease: status in the blood supply in endemic and nonendemic countries. Transfusion 1991; 31:547-557.

6. Dias JCP, Silveira AC. Enfermedad de Chagas en las Américas: situación actual y perspectivas. Rev Soc Bras Med Trop 2005; 38:5-13.

7. Moncayo A, Silveira AC. Current epidemiological trends for Chagas disease in Latin America and future challenges in epidemiology, surveillance and health policy. Mem Inst Oswaldo Cruz 2009; 104:17-30.

8. Moraes-Souza H, Martins PRJ, Pereira GA, Ferreira-Silva MM, Abud MB Significado dos testes sorológicos positivos e indeterminados para doença de Chagas na triagem dos doadores de sangue do Hemocentro Regional de Uberaba. Rev Bras Hematol Hemoter 2006; 28:105-109.

9. Schmunis GA, Cruz JR. Safety of the blood supply in Latin América. Clin Microbiol Rev 2005; 18:12-29.

10. Organización Panamericana de la Salud. Estimación cuantitativa de la enfermedad de Chagas en las Américas (OPS/HDM/CD/425-06); 2006.

11. Melo AS, Lorena VMB, Moraes AB, Pinto MB, Gomes YM. The prevalence of chagasic infection among blood donors in the State of Pernambuco, Brazil. Rev Bras Hematol Hemoter 2009; 31: 69-73.
12. Baruffa G. Prevalência da infecção chagásica no banco de sangue da Santa Casa de Misericórdia de Pelotas, Rio Grande do Sul, Brasil. Rev Inst Med Trop São Paulo 1979; 21:37-42.

13. Araújo AB, Vianna EES, Berne MEA. Anti-Trypanosoma cruzi Antibody Detection in Blood Donors in the Southern Brazil. Braz J Infect Dis 2008; 12:480-482.

14. Salles NA, Sabino EC, Barreto CC. Descarte de bolsas de sangue e prevalência de doenças infecciosas em doadores de sangue da Fundação Pró-Sangue/ Hemocentro de São Paulo. Rev Panam Salud Publica 2003; 13: 111-115.

15. Moraes-Souza H. Estudo do metabolismo e viabilidade do sangue fresco e preservado tratado pela violeta de genciana [tese de doutorado]. São Paulo (SP): Universidade de Federal de São Paulo; 1985.

16. Schofield CJ, Janin J, Salvatella R. The future of Chagas disease control. Trends in Parasitol 2006; 22:583-588.

17. Moraes-Souza H, Bordin JO. Strategies for prevention of transfusionassociated Chagas'disease. Transfus Med Rev 1996; 10:161-170.

18. Saez-Alquezar A, Otoni MM, Sabino EC, Salles NA, Chamone DF. Programas de control externo de la calidad en serologia desarrollados en América Latina con el apoyo de la OPS entre 1997 y 2000. Rev Panam Salud Publica 2003; 13:91-102.

19. Saez-Alquezar A, Murta M, Pereira Marquez W, Rodrigues da Silva G. Resultados de un programa de control de calidad externo del tamizaje serologica de anticuerpos contra Trypanosoma cruzi en donantes de sangre en Brasil. Rev Panam Salud Publica 2003; 13:129-137.

20. Schmunis GA. Epidemiology of Chagas disease in non-endemic countries: the role of international migration. Mem Inst Oswaldo Cruz 2007; 10: 75-85.

21. Blood Products Advisory Committee. Transcripts of the September 12 2002, Blood Products Advisory Committee Meeting. Rockuble (MD): CBER, FDA; 2002.

22. Leiby DA, Fucci MH, Stumpf RJ. Trypanosoma cruzi in a low-to moderaterisk blood donor population. Transfusion 1999; 39:310-315.

23. Oliveira LR, Assis LLT, Matos AL, Calil MCFR Moraes-Souza H. Reativação de doença de Chagas com envolvimento de Sistema Nervoso Central durante tratamento de linfoma não-Hodgkin. Rev Bras Hematol Hemoter 2010; 32: 269-272.

24. Schmunis GA. Riesgo de la enfermedad de Chagas a través de las transfusiones en las Américas. Medicina (Buenos Aires) 1999; 59: 125-134.

25. Kerndt PR, Weskin HA, Kirchhoff LV, Steurer F, Waterman SH, Nelson JM, et al. Prevalence of antibody to Trypanosoma cruzi among blood donors in Los Angeles, California. Transfusion 1991; 31:814-818.

26. Dias JCP. Southern Cone Initiative for the elimination of domestic populations of Triatoma imfestans and the interruption of transfusional Chagas' disease. Historical aspects, present situation and perspectives. Mem Inst Oswaldo Cruz 2007; 102: 11-18.

27. Salles NA, Sabino EC, Cliquet MG, Eluf-Neto J, Mayer A, Almeida-Neto C, et al. Risk of exposure to Chagas'disease among seroreactive Brazilian blood donors. Transfusion 1996; 36:969-973.

28. Leiby DA. Blood screening for Trypanosoma cruzi antibodies: US experience. PAHO/HDM/CD/CHA, OMS; 2007.

29. Ferreira-Silva MM, Pereira GA, Lages-Silva E, Moraes-Souza H. Socioepidemiological screening of serologically ineligible blood donors due to Chagas disease for the definition of inconclusive cases. Mem Inst Oswaldo Cruz 2010; 105(6): 800-805. 